\title{
Transcervical intrauterine levobupivacaine infusion or paracervical block for pain control during endometrial biopsy
}

\author{
NERMIN KÖŞÜŞ ${ }^{1}$, AYDIN KÖŞÜŞ $^{1}$, AYŞE GÜLER $^{2}$, SERAP A. SIMAVLI $^{1}$ and NILGÜN Ö. TURHAN ${ }^{3}$ \\ ${ }^{1}$ Department of Obstetrics and Gynecology, Faculty of Medicine, Fatih University, Ankara; \\ ${ }^{2}$ Deparment of Obstetrics and Gynecology, Faculty of Medicine, Yüzüncü Yıl University, Van; \\ ${ }^{3}$ Department of Obstetrics and Gynecology, Faculty of Medicine, Muğla University, Muğla, Turkey
}

Received September 5, 2011; Accepted December 19, 2011

DOI: $10.3892 /$ etm.2012.463

\begin{abstract}
The aim of this study was to determine pain during endometrial biopsy by comparing the use of intrauterine instillation of levobupivacaine or paracervical block with a placebo in a randomized, double-masked trial in premenopausal and postmenopausal women. A total of 90 women were enrolled in the study. Patients were allocated to either the control or case groups. Group 1 consisted of 30 cases with intrauterine anesthesia with $5 \mathrm{ml} 0.5 \%$ levobupivacaine. Group 2 consisted of 30 patients who underwent paracervical block with lidocaine. No analgesic agent was given to the remaining 30 patients; these cases comprised the control group. The primary outcome measures were pain or discomfort experienced during the procedure. When the pain scores of the different groups were compared, the scores in the intrauterine levobupivacaine and paracervical block groups were found to be significantly lower compared to those in the control group. There was no difference between the levobupivacaine and paracervical block groups in terms of pain scores. There was a marked positive correlation between biopsy indications and pain scores. Pain scores were lower in cases with the indication of polymenorrhea, hypermenorrhea and metrorraghia compared to those in the cases with other indications. In conclusion, the transcervical intrauterine instillation of levobupivacaine or paracervical block with lidocaine brings about pain relief during and after endometrial biopsy.
\end{abstract}

\section{Introduction}

Endometrial biopsy is a common procedure for the investigation of many gynecological disorders, including abnormal

Correspondence to: Dr Nermin Köşüş, Department of Obstetrics and Gynecology, Faculty of Medicine, Fatih University, Ostim Mah. 1290. sok, Nevbahar Konutları A7 Block, No 43 Yenimahalle, Ankara, Turkey

E-mail: nerminkosus@gmail.com

Key words: levobupivacaine, paracervical block, endometrial biopsy, pain uterine bleeding, postmenopausal bleeding, abnormal cytology and infertility $(1,2)$. The majority of women experience some degree of discomfort and pain during the procedure. Pain may occur during dilatation of the cervix for insertion of the catheter and during endometrial biopsy, which further aggravates pain by inducing uterine contraction $(1,2)$.

The paracervical block relieves pain in the lower part of the uterus and cervix by blocking nerve impulses that are conveyed through the Frankenhäuser plexus. However, it may not be effective for pain in the upper part of the uterus, which has a different innervation. Intrauterine anesthesia, by the infusion of a local anesthetic into the uterine cavity, has a theoretical action by blocking nerve endings in the uterine corpus and fundus $(3,4)$.

The effectiveness of intrauterine anesthesia for pain relief in gynecological procedures that involve the uterine cavity has been demonstrated in many studies (5-9). The intrauterine instillation of a topical anesthetic is easy, relatively painless, and promising for adequate analgesia during endometrial biopsy. This technique could be an ideal method of anesthesia for endometrial biopsies.

Levobupivacaine is a long-acting local anesthetic agent. Levobupivacaine takes a while to take effect; however, it has a longer duration of action.

The goal of this study was to determine pain during endometrial biopsy by comparing the intrauterine instillation of levobupivacaine or paracervical block with a placebo in a randomized, double-masked trial in premenopausal and postmenopausal women. Also types and incidence of possible adverse events were reported.

\section{Materials and methods}

Study population and exclusion/inclusion criteria. This was a randomized, placebo-controlled trial carried out in the Obstetrics and Gynecology Department, Faculty of Medicine, Fatih University, Turkey between September 2009 and July 2010. The aim of this study was to compare the efficacy of intrauterine levobupivacaine instillation, paracervical block and a placebo for pain control in patients undergoing endometrial biopsy. The study was approved by the human ethics committee of the university. The study population comprised women with abnormal uterine bleeding who were scheduled 
for endometrial curettage or women who would have control biopsies before surgery due to other pathologies. Patients who were virgins, or those who had an American Society of Anesthesiologists (ASA) physical status class of $>$ II, acute cervicitis, profuse uterine bleeding, known allergy to levobupivacaine, a history of impaired liver function, were pregnant, had cervical stenosis or vaginismus or were unable to understand how to score a $10-\mathrm{cm}$ visual analog scale (VAS) pain score were excluded from the study. Suitable patients were informed as regards the study protocol and signed informed consent was obtained from all patients.

A total of 90 women were included in the study. Before the procedure, patient demographics such as age, gravida, parity, menopausal status and biopsy indications were recorded. Endometrial thickness in patients was measured by transvaginal sonography before the procedure. Patients were allocated to either the control or case groups by simple randomization prior to endometrial biopsy. Group 1 comprised cases with intrauterine anesthesia with $5 \mathrm{ml} 0.5 \%$ levobupivacaine (Chirocaine; Abbott, Tipperary, Republic of Ireland). Group 2 comprised patients who underwent paracervical block with lidocaine (Aritmal ampule 2\%; Biosel, Istanbul, Turkey). No analgesic agent was given to the remaining 30 patients; these cases comprised the control group.

Biopsies. Biopsies were carried out with the Pipelle (Unimar, Wilton, CT, USA), a flexible plastic 3.1-mm diameter catheter. The same technique was used to sample the endometrium by resident doctors to minimize the risk of technical variation.

The procedures were performed under the aseptic technique as follows: the patient was placed in a modified lithotomy position. A sterile bivalve speculum was introduced into the vagina for visualization of the cervix. The cervix and vagina were then cleansed with betadine solution (Betadine; Purdue Pharma LP, Stamford, CT, USA). Each patient in group 1 received an intrauterine injection of $0.5 \%$ levobupivacaine before endometrial sampling. The solution $(5 \mathrm{ml})$ was instilled through the endocervix into the uterine cavity using an 18-gauge angiocatheter. The angiocatheter was left in place for 15 min before it was withdrawn to decrease backflow and allow the anesthetic to take effect. In group 2, paracervical block was performed with $5 \mathrm{ml} 2 \%$ lidocaine solution. Local anesthetic was applied at $0.5-1 \mathrm{~cm}$ depth of the cervicovaginal junction at the four and eight o'clock positions without application of tenaculum to the cervix. We waited for $5 \mathrm{~min}$ before endometrial sampling to allow the anesthetic to take effect. No anesthetic was given to the control group. The Pipelle was pushed into the uterine cavity for three passes to ensure complete sampling in all patients.

All patients were observed for $60 \mathrm{~min}$ in a recovery room. None of the patients enrolled in the study had received any oral or parenteral analgesic drugs. All tissue specimens were sent for cytopathological examination. All tissue specimens were analyzed by pathologists who were blinded to the test solution.

VAS pain ratings. The primary outcome measures were pain or discomfort experienced during the procedure. Pain was assessed using a $10-\mathrm{cm}$ visual analogue pain scale. Patients were asked to rate their pain levels on a VAS, marking an
' $\mathrm{X}$ ' on a $10-\mathrm{cm}$ line $(0 \mathrm{~cm}$, no pain; $10 \mathrm{~cm}$, unbearable pain). The pain score was measured during the uterine curettage. To control for possible confounding as the result of a nonequal distribution of women with insertional pain, we excluded those subjects who experienced pain from speculum insertion. In those cases where the patient had intolerable pain, the procedure was terminated immediately, and the pain score was recorded. Scores were measured from the left and recorded. All observed adverse effects were recorded until the patients were discharged.

Statistical analysis. The statistical analyses were carried out using the SPSS 15.0 statistical software package. Following the entering of patient data into the computer, all the necessary diagnostic checks and corrections were performed. The conformity of the measured values to normal distribution was examined graphically and using the Shapiro-Wilk test. In presenting descriptive statistics, numbers and percentages were used for categorical variables, and median [interquartile range (IQR)] values were used for the data. For the comparison of normally distributed data, ANOVA and post hoc Bonferoni tests were used. The Kruskal-Wallis test and the Bonferoni-corrected Mann-Whitney test were used to compare the data that was not distributed normally. Spearman's correlation analysis was used for parameters that affect pain scores. A two-tailed p-value of $<0.05$ was considered to indicate a statistically significant difference.

\section{Results}

A total of 90 women were included in the study and divided into three groups (30 cases per group) randomly. Mean age, gravida, parity, and menopausal status of the women in the three groups were similiar. Endometrial thickness in patients was measured by transvaginal sonography before the procedure. Endometrial thickness was significantly lower in Group 2 than group 1 and the control group. The demographic and clinical characteristics of the groups are summarized in Table I.

When groups were compared for biopsy indications, there was no difference between groups. Endometrial biopsy due to hypermenorrhea was higher in the levobupivacaine group. Control biopsy prior to surgery due to other gynecological pathologies was higher in group 2 and the control group ( $p=0.003$ vs. $p=0.002$, respectively) than in group 1 (Table II).

When pain scores between the groups were compared, scores in the intrauterine levobupivacaine and paracervical block groups were found to be significantly lower than those in the control group (Fig. 1) $(Z=2.761 ; p=0.006$ vs. $Z=3.310$; $\mathrm{p}=0.001$, respectively). There was no difference between the levobupivacaine and paracervical block groups in terms of pain scores (Fig. 2) $(\mathrm{Z}=0.305$; $\mathrm{p}=0.760)$. The distribution of pain scores among the groups is shown in Table III.

There was a marked positive correlation between biopsy indications and pain scores ( $r h o=0.648 ; \mathrm{p}<0.001$ ). Pain scores were lower in cases with the indication of polymenorrhea, hypermenorrhea and metrorraghia than those with other indications. There was mild positive correlation between pain scores and type of anesthesia used (rho $=0.344 ; \mathrm{p}=0.001$ ) (Table IV). 
Table I. Demographic and clinical characteristics of the groups.

\begin{tabular}{lccc}
\hline Characteristic & $\begin{array}{c}\text { Levobupivacaine } \\
(\mathrm{n}=30)\end{array}$ & $\begin{array}{c}\text { Paracervical block } \\
(\mathrm{n}=30)\end{array}$ & $\begin{array}{c}\text { Control } \\
(\mathrm{n}=30)\end{array}$ \\
\hline Age (years; mean $\pm \mathrm{SD})$ & $44.6 \pm 7.9$ & $45.3 \pm 10.4$ & $47.8 \pm 9.2$ \\
Gravida [n; median (IQR)] & $3(2)$ & $2(3)$ & $3(2)$ \\
Parity [n; median (IQR)] & $2(1)$ & $2(2)$ & $2(1)$ \\
Menopausal status & & $23(76.7)$ & 0.412 \\
Premenopause (\%) & $24(80.0)$ & $7(23.3)$ & 0.532 \\
Postmenopause (\%) & $6(20.0)$ & $1(3.3)$ & 0.938 \\
Endom. thickness & $8(26.7)$ & $29(96.7)$ & $9(30.7)$ \\
$<5$ mm $(\%)$ & $22(73.3)$ & $21(70.0)$ \\
$\geq 5$ mm $(\%)$ & & $0.019^{\mathrm{a}}$ \\
\hline
\end{tabular}

aSignificant difference between levobupivacaine vs. paracervical block and control group. IQR, interquartile range. Endom., endometrial.

Table II. Biopsy indications according to groups.

\begin{tabular}{|c|c|c|c|c|}
\hline $\begin{array}{l}\text { Biopsy } \\
\text { indication }\end{array}$ & $\begin{array}{c}\text { Levobupivacaine } \\
\mathrm{n}(\%)\end{array}$ & $\begin{array}{c}\text { Paracervical } \\
\mathrm{n}(\%)\end{array}$ & $\begin{array}{c}\text { Control } \\
\mathrm{n}(\%)\end{array}$ & p-value \\
\hline Menorrhagia & $7(23.3$ & $3(10.0)$ & $4(13.3)$ & 0.343 \\
\hline Metrorrhagia & $3(10.0$ & $3(10.0)$ & $1(3.3)$ & 0.492 \\
\hline Menometrorrhagia & $7(23.3)$ & $10(33.3)$ & $12(40.0)$ & 0.380 \\
\hline Postmenopausal bleeding & $6(20.0)$ & $7(23.3)$ & $6(20.0)$ & 0.935 \\
\hline Hypermenorrhea & $5(16.7)$ & $0(0.0)$ & $0(0.0)$ & $0.003^{\mathrm{a}}$ \\
\hline Polymenorrhea & $2(6.7)$ & $0(0.0)$ & $0(0.0)$ & 0.106 \\
\hline Pre-op control & $0(0.0)$ & $7(23.3)$ & $7(23.3)$ & $0.002^{\mathrm{a}}$ \\
\hline Total & $30(100.0)$ & $30(100.0)$ & $30(100.0)$ & 0.944 \\
\hline
\end{tabular}

${ }^{a}$ Significant difference between levobupivacaine vs. paracervical block and control group.

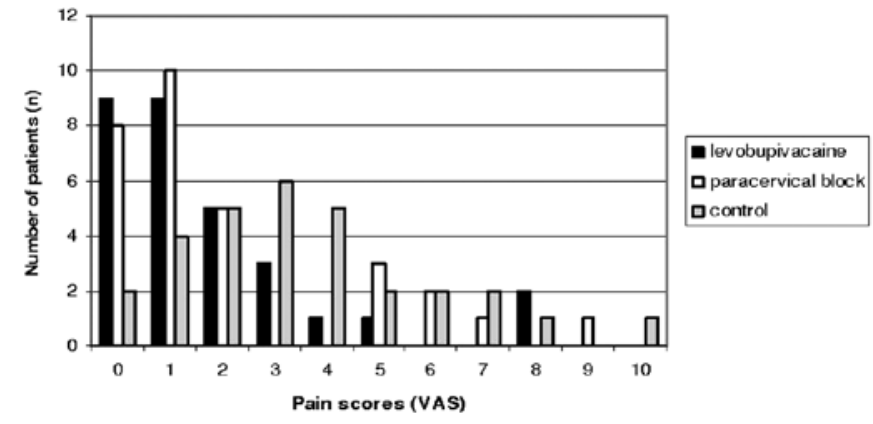

Figure 1. Distribution of pain scores among groups.

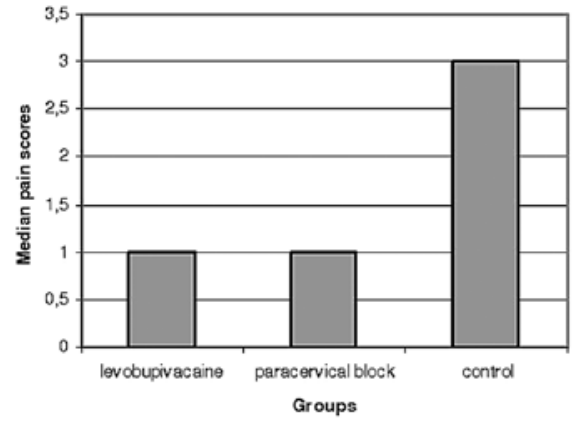

Figure 2. Median pain scores by group.
The majority of the biopsy results were proliferative $(n=28$; $31.1 \%)$ and secretory $(n=19 ; 21.1 \%)$ endometrium. Simple hyperplasia was found only in three cases (3.3\%). Due to insufficient material, inconclusive results were observed in the control and paracervical groups $(n=6 ; 20 \%$ for each group) (Table V).

\section{Discussion}

Endometrial biopsy is one of the essential but painful procedures of gynecology. Procedural pain appears to arise from two separate anatomical structures, the cervix and the uterus. The cervix and uterus are richly innervated and pain perception 
Table III. Distribution of pain scores by group.

\begin{tabular}{|c|c|c|c|c|}
\hline Pain score & $\begin{array}{c}\text { Levobupivacaine } \\
\text { n }(\%)\end{array}$ & $\begin{array}{c}\text { Paracervical block } \\
\mathrm{n}(\%)\end{array}$ & $\begin{array}{l}\text { Control } \\
\mathrm{n}(\%)\end{array}$ & p-value \\
\hline 0 & $9(30.0)$ & $8(26.7)$ & $2(6.7)$ & 0.057 \\
\hline 1 & $9(30.0)$ & $10(33.3)$ & $4(13.3)$ & 0.164 \\
\hline 2 & $5(16.7)$ & $5(16.7)$ & $5(16.7)$ & 1.000 \\
\hline 3 & $3(10.0)$ & $0(0.0)$ & $6(20.0)$ & $0.011^{\mathrm{a}}$ \\
\hline 4 & $1(3.3)$ & $0(0.0)$ & $5(16.7)$ & 0.016 \\
\hline 5 & $1(3.3)$ & $3(10.0)$ & $2(6.7)$ & 0.572 \\
\hline 6 & $0(0.0)$ & $2(6.7)$ & $2(6.7)$ & 0.189 \\
\hline 7 & $0(0.0)$ & $1(3.3)$ & $2(6.7)$ & 0.242 \\
\hline 8 & $2(6.7)$ & $0(0.0)$ & $1(3.3)$ & 0.242 \\
\hline 9 & $0(0.0)$ & $1(3.3)$ & $0(0.0)$ & 0.330 \\
\hline 10 & $0(0.0)$ & $0(0.0)$ & $1(3.3)$ & 0.330 \\
\hline Median (IQR) & $1(2.25)$ & $1(2.75)$ & $3(3)$ & $0.002^{\mathrm{b}}$ \\
\hline
\end{tabular}

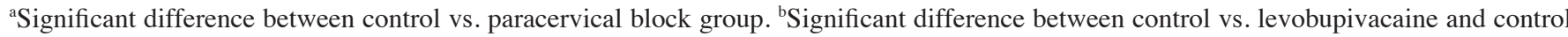
vs. paracervical block group. IQR, interquartile range.

Table IV. Correlation analysis of parameters that affect pain score.

\begin{tabular}{|c|c|c|c|c|c|c|c|}
\hline & Age & Gravida & Parity & Indication & $\begin{array}{c}\text { Endometrial } \\
\text { thickness }\end{array}$ & $\begin{array}{c}\text { Type of } \\
\text { anesthesia }\end{array}$ & $\begin{array}{l}\text { Pain } \\
\text { score }\end{array}$ \\
\hline \multicolumn{8}{|l|}{ Age } \\
\hline Rho & - & $0.454^{\mathrm{a}}$ & 0.361 & 0.361 & 0.026 & 0.321 & 0.189 \\
\hline p-value & - & 0.026 & 0.083 & 0.050 & 0.891 & 0.142 & 0.317 \\
\hline \multicolumn{8}{|l|}{ Gravida } \\
\hline Rho & $0.454^{\mathrm{a}}$ & - & $0.633^{\mathrm{a}}$ & $0.557^{\mathrm{a}}$ & 0.152 & 0.183 & 0.083 \\
\hline p-value & 0.026 & - & 0.001 & 0.005 & 0.479 & 0.212 & 0.699 \\
\hline \multicolumn{8}{|l|}{ Parity } \\
\hline Rho & 0.361 & $0.633^{\mathrm{a}}$ & - & 0.342 & 0.053 & 0.243 & 0.188 \\
\hline $\mathrm{p}$-value & 0.083 & 0.001 & - & 0.102 & 0.805 & 0.156 & 0.380 \\
\hline \multicolumn{8}{|c|}{ Indication } \\
\hline Rho & 0.361 & $0.557^{\mathrm{a}}$ & 0.342 & - & $0.257^{\mathrm{a}}$ & 0.026 & $0.648^{\mathrm{a}}$ \\
\hline p-value & 0.050 & 0.005 & 0.102 & - & 0.014 & 0.809 & $<0.001$ \\
\hline p-value & 0.571 & 0.164 & 0.218 & 0.401 & $<0.001$ & 0.211 & 0.709 \\
\hline \multicolumn{8}{|c|}{$\begin{array}{l}\text { Endometrial } \\
\text { thickness }\end{array}$} \\
\hline Rho & 0.026 & 0.152 & 0.053 & $0.257^{\mathrm{a}}$ & - & 0.034 & 0.172 \\
\hline p-value & 0.891 & 0.479 & 0.805 & 0.014 & - & 0.750 & 0.104 \\
\hline \multicolumn{8}{|c|}{$\begin{array}{l}\text { Type of } \\
\text { anesthesia }\end{array}$} \\
\hline Rho & 0.154 & 0.085 & 0.112 & 0.026 & 0.034 & - & $0.344^{\mathrm{a}}$ \\
\hline p-value & 0.412 & 0.622 & 0.521 & 0.809 & 0.750 & - & 0.001 \\
\hline \multicolumn{8}{|c|}{ Pain score } \\
\hline Rho & 0.189 & 0.083 & 0.188 & $0.648^{\mathrm{a}}$ & $0.172^{\mathrm{a}}$ & $0.344^{\mathrm{a}}$ & - \\
\hline p-value & 0.317 & 0.699 & 0.380 & $<0.001$ & 0.104 & 0.001 & - \\
\hline
\end{tabular}

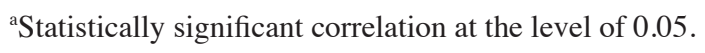


Table V. Histopathological results of cases.

\begin{tabular}{|c|c|c|c|c|}
\hline Endometrial biopsy results & $\begin{array}{c}\text { Levobupivacaine } \\
\text { n }(\%)\end{array}$ & $\begin{array}{c}\text { Paracervical } \\
\mathrm{n}(\%)\end{array}$ & $\begin{array}{c}\text { Control } \\
\mathrm{n}(\%)\end{array}$ & $\begin{array}{l}\text { Total } \\
\mathrm{n}(\%)\end{array}$ \\
\hline Simple hyperplasia & $1(3.3)$ & $0(0.0)$ & $1(3.3)$ & $2(2.2)$ \\
\hline Proliferative endometrium & $12(10.0)$ & $5(13.4)$ & $11(33.4)$ & $28(31.1)$ \\
\hline Secretory endometrium & $6(20.0)$ & $6(20.0)$ & $7(23.3)$ & $19(21.1)$ \\
\hline Endometrial polyp & $2(6.7)$ & $0(0.0)$ & $0(0.0)$ & $2(2.2)$ \\
\hline Stromal glandular destruction & $3(10.0)$ & $0(0.0)$ & $0(0.0)$ & $3(3.3)$ \\
\hline Chronic endometritis & $1(3.3)$ & $5(16.6)$ & $2(6.7)$ & $8(8.9)$ \\
\hline Menstrual endometrium & $3(10.0)$ & $0(0.0)$ & $0(0.0)$ & $3(3.3)$ \\
\hline Endometrial tissue fragments & $2(6.7)$ & $1(3.3)$ & $1(3.3)$ & $4(4.5)$ \\
\hline Endometrium under drug effect & $0(0.0)$ & $3(10.0)$ & $2(6.7)$ & $5(5.6)$ \\
\hline Atrophic endometrium & $0(0.0)$ & $2(6.7)$ & $0(0.0)$ & $2(2.2)$ \\
\hline Blood, fibrin and mucus & $0(0.0)$ & $2(6.7)$ & $0(0.0)$ & $2(2.2)$ \\
\hline Insufficient material & $0(0.0)$ & $6(20.0)$ & $6(20.0)$ & $12(13.3)$ \\
\hline Total & $30(100.0)$ & $30(100.0)$ & $30(100.0)$ & $90(100.0)$ \\
\hline
\end{tabular}

from the cervix and the corpus of the uterus appears to pass through two distinct neural pathways; Frankenhäuser plexus (parasympathetic S2-4) supplying the cervix and lower uterus, and sympathetic nerves via the infundibulopelvic ligament from the ovarian plexus supplying the uterine fundus $(3,4)$.

Procedural pain may occur during dilatation of the cervix for insertion of the catheter and during endometrial biopsy, which further aggravates pain by inducing uterine contraction. The paracervical block aids in decreasing pain from cervical origin (10-12). However, it has been found to be ineffective in reducing pain arising from the uterine corpus and carries a risk of inducing bradycardia, hypotension, convulsion, respiratory arrest, and death $(13,14)$. On the other hand, a local or topical anesthetic injected into the uterine cavity may inhibit nerve responses and decrease pain primarily arising from the body of the uterus.

There is controversy over the efficacy of transcervical intrauterine anaesthesia. Previous studies have investigated the use of different local anesthetics (i.e., lidocaine, mepivacaine) to lessen the pain experienced with endometrial biopsy and other intrauterine procedures such as hysteroscopy, fractional curettage, hysterosalpingography (HSG) and removal of a lost intrauterine device (IUD) (6-9). The intrauterine instillation of local anesthetic has variously been reported to be ineffective or effective in reducing pain when compared with saline in randomised trials $(6,7,15-17)$. However, in the majority of studies, local anesthetic injected into the uterine cavity has been demonstrated to be effective in decreasing patient pain associated with these intrauterine procedures.

A study of a $2-\mathrm{ml}$ infusion of $2 \%$ lidocaine, in addition to oral naproxen sodium, prior to HSG demonstrated no reduction in pain and the possibility of increased postprocedural pain (18). Also, in the study by Zupi et al (6), with 45 women, no statistically significant reduction in pain was found.

In another study, Guney et al (19) compared the effects of a local anesthetic and placebo for the removal of a 'lost' IUD. A significant difference was found in terms of pain reduction with the use of intrauterine topical local anesthetic either during or immediately after the procedure. However, perception of pain at 20 min after the procedure was significantly higher in the lidocaine group compared with the placebo group.

Cicinelli et al (7) randomly assigned 80 women to receive $2 \mathrm{ml}$ of $2 \%$ mepivacaine or normal saline with a 5-min delay before an office hysteroscopy and/or endometrial biopsy. Their results showed a statistically significant reduction in pain in women receiving the mepivacaine infusion. They reported considerably higher $(32.5 \%)$ incidence of vasovagal reaction in their placebo group. Similar results were observed by Dogan et al (9). They found that the combination of local lidocaine and oral naproxen sodium significantly reduced patient discomfort during an endometrial biopsy.

Trolice et al (8) randomly assigned 57 perimenopausal and postmenopausal women to receive either intrauterine lidocaine or normal saline before having an office endometrial biopsy. Five milliliters of $2 \%$ lidocaine were infused with a 3-min time delay before obtaining the biopsy. They found a statistically significant reduction in pain in women receiving the lidocaine infusion. They concluded that local anesthetic injected into the uterine cavity is effective in decreasing patient pain associated with these intrauterine procedures.

The time interval allowed for the local anesthetic to become effective is also important. The peak anesthetic effect following topical application of $1 \%$ lidocaine occurs within 10 min (20). Edelman et al (20) randomly assigned 80 women to receive $10 \mathrm{ml} 1 \%$ lidocaine or saline with a 3 -min delay in first-trimester abortions and did not observe a reduction in pain during or after suction aspiration. The 3-min waiting period may be too short. It is also possible that tubal extravasation of high-dose lidocaine might have caused peritoneal irritation. In our study, as explained in Materials and methods, we waited 5 min following the injection of lidocaine and $15 \mathrm{~min}$ following the injection of levobupivacaine before removing the catheter. The volume of anesthetic used in our study was $5 \mathrm{ml}$.

Rattanachaiyanont et al (21) found statistically significant reductions in pain when a combination of paracervical block 
and intrauterine anesthesia was used before fractional curettage. We did not apply paracervical block, as cervical dilation was not necessary in our patients. Cases with cervical stenosis who required cervical dilation were excluded from the study.

Since pain is a subjective symptom, it is difficult to evaluate and anxiety may be a potential confounder. Ethnic and cultural differences between the patients may affect pain perception and tolerance. Measurement of anticipatory pain may therefore be of value in studies on pain for determination of true pain. It is likely that the speculum insertion measurement is a surrogate for a patient's overall tolerance of pain and/or anxiety. Pain with speculum insertion occurs in many conditions such as dyspareunia, vulvar vestibular syndrome, and vaginismus $(21,22)$. To control for possible confounding as the result of a nonequal distribution of women with insertional pain, we excluded those subjects who experienced pain from speculum insertion.

Endometrial biopsy is an essential office procedure to collect tissue for histological evaluation of the endometrium. Patient acceptability and compliance with the procedure may be difficult due to associated pain. According to our MEDLINE search, this is the first study to evaluate the efficacy of intrauterine topical levobupivacaine installation for endometrial biopsy. A limitation of our study is the small sample number; however, analysis of our data showed a statistically significant reduction in pain during endometrial biopsy with intrauterine levobupivacaine and lidocaine in premenopausal and postmenopausal women, regardless of parity. Although instillation may lengthen the procedure, the reduction in patient discomfort outweighs the time factor. Among the local anesthetic agents, lidocaine has an advantage over levobupivacaine, as a shorter time is needed for the initiation of its effects. The intrauterine topical instillation of anesthetic also did not affect pathology results.

In conclusion, the transcervical intrauterine topical instillation of levobupivacaine or paracervical block with lidocaine brings about pain relief during and after endometrial biopsy. Therefore, it appears to be a beneficial method. However, further studies with larger series are required to evaluate the effectiveness of intrauterine anesthesia, for determination of optimal concentration, volume and waiting time according to local anesthesia and also for applicability of the method to other intrauterine procedures.

\section{References}

1. Chambers JT and Chambers SK: Endometrial sampling: when? Where? Why? With what? Clin Obstet Gynecol 35: 28-39, 1992.

2. Fothergill DJ, Brown VA and Hill AS: Histological sampling of the endometrium - a comparison between formal curettage and the Pipelle sampler. Br J Obstet Gynaecol 99: 779-780, 1992.

3. Rogers RM: Basic pelvic neuroanatomy. In: Chronic Pelvic Pain: an Integrated Approach. Steege JF, Metzger DA and Levy BS (eds). WB Saunders Company, Philadelphia, PA, pp31-58, 1998.
4. Moore KL, Dalley AF and Agur AMR: Pelvis and Perineum. Pelvic Viscera. In: Clinically Oriented Anatomy. 6th edition. Lippincott Williams \& Wilkins, Baltimore, MD, pp362-402, 2010.

5. Cicinelli E, Didonna T, Fiore G, Parisi C, Matteo M and Castrovilli G: Topical anesthesia for hysteroscopy in postmenopausal women. J Am Assoc Gynecol Laparosc 4: 9-12, 1996.

6. Zupi E, Luciano AA, Valli E, Marconi D, Maneschi F and Romanini C: The use of topical anesthesia in diagnostic hysteroscopy and endometrial biopsy. Fertil Steril 63: 414-416, 1995.

7. Cicinelli E, Didonna T, Ambrosi G, Schonauer LM, Fiore G and Matteo MG: Topical anaesthesia for diagnostic hysteroscopy and endometrial biopsy in postmenopausal women: a randomised placebo-controlled double-blind study. Br J Obstet Gynaecol 104: 316-319, 1997.

8. Trolice MP, Fishburne C Jr and McGrady S: Anesthetic efficacy of intrauterine lidocaine for endometrial biopsy: a randomized double-masked trial. Obstet Gynecol 95: 345-347, 2000.

9. Dogan E, Celiloglu M, Sarihan E and Demir A: Anesthetic effect of intrauterine lidocaine plus naproxen sodium in endometrial biopsy. Obstet Gynecol 103: 347-351, 2004.

10. Glantz J and Shomento S: Comparison of paracervical block techniques during first trimester pregnancy termination. Intl J Gynecol Obstet 72: 171-178, 2001.

11. Stubblefield P: Control of pain for women undergoing abortion. Intl J Gynecol Obstet 3: 131-140, 1989.

12. Wiebe E: Comparison of efficacy of different local anesthetics and techniques of local anesthesia in therapeutic abortions. Am J Obstet Gynecol 167: 131-134, 1992.

13. Miller L, Jensen MP and Stenchever MA: A double-blind randomized comparison of lidocaine and saline for cervical anesthesia. Obstet Gynecol 87: 600-604, 1996.

14. Chanrachakul B, Likittanasombut P, O-Prasertsawat P and Herabutya Y: Lidocaine versus plain saline for pain relief in fractional curettage: a randomized controlled trial. Obstet Gynecol 98: 592-595, 2001.

15. Lau WC, Tam WH, Lo WK and Yuen PM: A randomised doubleblind placebo-controlled trial of transcervical intrauterine local anaesthesia in outpatient hysteroscopy. Br J Obstet Gynaecol 107: 610-613, 2000.

16. Broadbent JA, Hill NC, Molnar BG, Rolfe KJ and Magos AL: Randomized placebo controlled trial to assess the role of intracervical lignocaine in outpatient hysteroscopy. Br J Obstet Gynaecol 99: 777-779, 1992.

17. Guler A, Kosus A, Kosus N and Sahin HG: Comparing the efficacy of intrauterine lidocaine and paracervical block for decreasing pain in endometrial biopsy. J Surg Arts 2: 1-10, 2009.

18. Costello M, Horrowitz S, Steigrad S, Saif N, Bennett M and Ekangaki A: Transcervical intrauterine topical local anesthetic at hysterosalpingography: a prospective randomized, doubleblinded, placebo-controlled trial. Fertil Steril 78: 1116-1122, 2002.

19. Guney M, Oral B and Mungan T: Efficacy of intrauterine lidocaine for removal of a 'lost' intrauterine device. Obstet Gynecol 108: 119-123, 2006.

20. Edelman A, Nichols MD, Leclair C, Astley S, Shy K and Jensen JT: Intrauterine lidocaine infusion for pain management in first trimester abortions. Obstet Gynecol 103: 1267-1272, 2004.

21. Rattanachaiyanont $M$, Leerasiri $P$ and Indhavivadhana $S$ : Effectiveness of intrauterine anesthesia for pain relief during fractional curettage. Obstet Gynecol 106: 533-539, 2005.

22. Bhatia K, Rustimov O, Adhikary M and Hill S: Transcervical intrauterine bupivacaine for the management of postoperative pain following endometrial balloon ablation - a pre-trial toxicity study. Gynecol Surg 6: 143-146, 2009. 